\title{
Titulo do Trabalho \\ MORFOMETRIA DA MICROBACIA HIDROGRÁFICA DO CÓRREGO BURACÃO, UBERABA-MG
}

\author{
Nome do Autor (a) Principal \\ Janaína Ferreira Guidolini \\ Nome (s) do Coautor (a) (s) \\ Marcus Vinícius Neves Araújo; Miguel Domingues Dias Júnior. \\ Nome (s) do Orientador (a) (s) \\ Teresa Cristina Tarlé Pissarra; Vera Lúcia Abdala \\ Instituição ou Empresa \\ Universidade Estadual Paulista "Júlio de Mesquita Filho" \\ Instituição (s) de Fomento \\ Coordenação de Aperfeiçoamento de Pessoal de Nível Superior \\ E-mail de contato \\ janaguidolini@gmail.com
}

Palavras-Chave - Análise das características morfológicas. Diagnóstico ambiental. Gestão de microbacias hidrográficas.

\section{INTRODUÇÃO}

As características geomorfológicas e o tipo de cobertura vegetal de uma bacia são muito importantes para se avaliar o comportamento hidrológico e sua influência na infiltração, deflúvio, evapotranspiração, escoamento superficial, dentre outros (TONELLO et al., 2006).

Segundo Antonelli e Thomaz (2007), pela análise morfométrica é possível revelar indicadores específicos para um determinado local, de forma a qualificarem as alterações ambientais, mediante o uso dos parâmetros calculados, tais como: densidade de drenagem, declividades, comprimento de cursos d'água, coeficiente de rugosidade $(\mathrm{RN})$, dentre outros.

\section{OBJETIVO GERAL}

O objetivo do presente estudo foi realizar o estudo morfométrico da microbacia do 
córrego Buracão, no município de Uberaba- MG.

\section{METODOLOGIA}

O estudo foi conduzido no município de Uberaba-MG, localizado no Triângulo Mineiro, entre a latitude Sul 19 39' 10 "e longitude Oeste 47은 18", numa microbacia inserida na área de proteção ambiental (APA) do rio Uberaba.

A microbacia do córrego Buracão possui uma área total de 2.945,86 ha, que corresponde a 5,57\% desta APA (Figura 1. Córrego Buracão, afluente do rio Uberaba). $\mathrm{Na}$ área foram computadas 33 nascentes perenes e a vazão estimada na foz (Q7/10) de $105 \mathrm{l} / \mathrm{s}$. Existem 1218,09 ha de área coberta com vegetação nativa, que significam $41,3 \%$ da microbacia, conforme imagem de satélite LANDSAT-7 de 10/2003 (SEMEA, 2004).

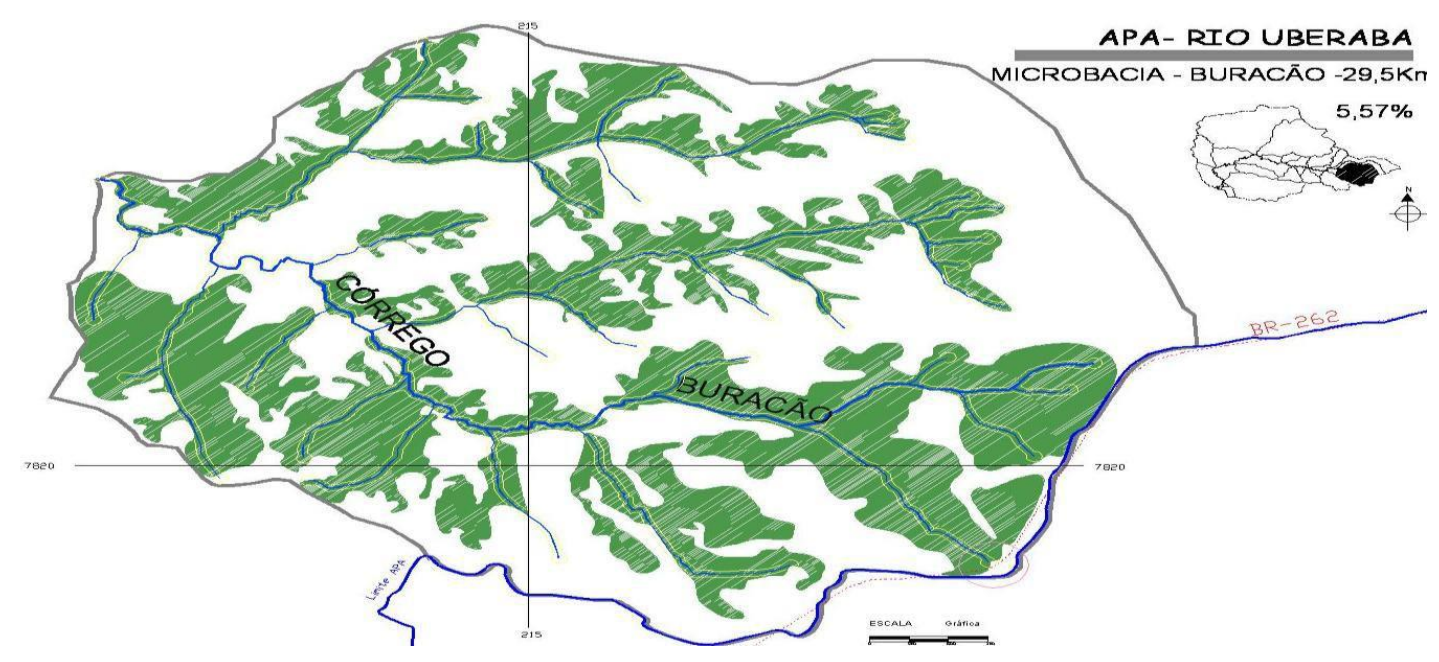

Figura 1 - Córrego Buracão, afluente do rio Uberaba Fonte: SEMEA, 2004.

O clima da região apresenta verão quente e chuvoso e inverno frio e seco. $O$ período chuvoso ocorre entre os meses de outubro e março e os meses com menor índice pluviométrico está entre setembro e abril. A região do Triângulo Mineiro apresenta temperatura média anual entre $20^{\circ} \mathrm{C}$ e $22^{\circ} \mathrm{C}$ e nos meses mais frios em torno de $18^{\circ} \mathrm{C}$ (TORRES, 2012).

A maioria dos solos da região de Uberaba apresenta textura média, variando de 
arenoso a argiloso; são classificados de forma geral como Latossolo de diferentes graus de fertilidade, com predominância do Latossolo Vermelho com $66,8 \%$ da área total (EMBRAPA, 1982). A topografia é caracterizada por superfícies pouco onduladas a planas, formada por arenito.

Para a caracterização morfométrica das redes de drenagem foi utilizado a partir de cartas topográficas do Instituto Brasileiro de Geografia e Estatística-IBGE e cálculos da microbacia determinou-se com uso do Software AutoCAD versão 2010 e também para a determinação em metros dos comprimentos das redes de drenagem da microbacia do Córrego Buracão. A ordem dos cursos d'água foi obtida utilizando os critérios desenvolvidos por Strahler (1952).

O coeficiente de compacidade $(\mathrm{Kc})$ ou índice de Gravelius relaciona a forma da bacia com um círculo. Constitui a relação entre o perímetro da bacia e a circunferência de um círculo de área igual à da bacia (LIMA et al. 1998). O Kc foi determinado através da equação 1 :

$\mathrm{Kc}=0,28(\mathrm{P} / \sqrt{ } \mathrm{A})$

Sendo: $\mathrm{Kc}$ o coeficiente de compacidade, $\mathrm{P}$ o perímetro $(\mathrm{m})$ e $\mathrm{A}$, área de drenagem $\left(\mathrm{m}^{2}\right)$. $\mathrm{O}$ fator forma $(\mathrm{Kf})$ relaciona a forma da bacia com a de um retângulo, correspondendo à razão entre a largura média e o comprimento axial da bacia. O F foi determinado através da equação 2:

$\mathrm{Kf}=\mathrm{A} / \mathrm{L}^{2}$

Sendo o Kf: fator de forma, A área de drenagem (22), L o comprimento do eixo da bacia (m).O índice de circularidade (Ic), simultaneamente ao coeficiente de compacidade, tende para a unidade à medida que a bacia se aproxima da forma circular e diminui à medida que a forma torna alongada. Pode ser calculado através da equação 3 :

$\mathrm{IC}=12,57^{\star} \mathrm{A} / \mathrm{P}^{2}$

Onde que Ic é o índice de circularidade, A a área de drenagem $\left(\mathrm{m}^{2}\right)$ e P o perímetro $(\mathrm{m})$. A densidade de drenagem (Dd) estima a maior ou menor velocidade com que a água deixa a bacia hidrográfica, sendo assim, o índice que indica o grau de desenvolvimento do sistema de drenagem (CARDOSO et al., 2006). O índice foi determinado utilizando a equação 4 :

$\mathrm{Dd}=\mathrm{Lt} / \mathrm{A}$ 
Sendo $\mathrm{Dd}$ a densidade de drenagem $\left(\mathrm{km} \mathrm{km}^{-2}\right)$, Lt comprimento total de todos os canais $(\mathrm{km})$ e $\mathrm{A}$, a área de drenagem $\left(\mathrm{km}^{2}\right)$.

\section{RESULTADOS}

Os índices físicos e morfométricos para a microbacia do Córrego Buracão podem ser observados na (Tabela 1. Índices físicos e morfométricos da microbacia hidrográfica do córrego Buracão, afluente do rio Uberaba-MG).

Tabela 1 - Índices físicos e morfométricos da microbacia hidrográfica do córrego Buracão, afluente do rio Uberaba-MG.

\begin{tabular}{|c|c|c|}
\hline Índices morfométricos & Unidade & Valores \\
\hline Área & $\mathrm{Km}^{2}$ & 29,5 \\
\hline Perímetro & $\mathrm{Km}$ & 22,2 \\
\hline Comprimento rede de drenagem principal & $\mathrm{Km}$ & 24,10 \\
\hline Comprimento $1^{1}$ ordem & $\mathrm{Km}$ & 10,5 \\
\hline Comprimento $2^{\text {a }}$ ordem & $\mathrm{Km}$ & 9,7 \\
\hline Comprimento $3^{\text {a }}$ ordem & $\mathrm{Km}$ & 2,6 \\
\hline Comprimento $4^{\text {a }}$ ordem & $\mathrm{Km}$ & 1,3 \\
\hline Maior largura & $\mathrm{Km}$ & 5,9 \\
\hline Maior comprimento & $\mathrm{Km}$ & 7,1 \\
\hline Largura média & $\mathrm{Km}$ & 4,9 \\
\hline Amplitude altimétrica & $\mathrm{m}$ & 139 \\
\hline Coeficiente de compacidade (Kc) & --- & 1,15 \\
\hline Fator forma $(\mathrm{Kf})$ & --- & 0,7 \\
\hline Densidade de drenagem (Dd) & $\mathrm{Km} \cdot \mathrm{Km}-2$ & 0,81 \\
\hline Sinuosidade do curso principal (Sin) & --- & 1,27 \\
\hline Declividade de bacia & $\%$ & 2,00 \\
\hline Declividade do curso principal & $\%$ & 2,00 \\
\hline Índice de circularidade (Ic) & --- & 0,5 \\
\hline Declividade média & $\%$ & 10,65 \\
\hline Coeficiente de rugosidade & --- & 11,93 \\
\hline
\end{tabular}

A rede de drenagem da bacia caracteriza-se por ter um padrão dendrítico. A microbacia do córrego Buracão possui área total de $29,5 \mathrm{~km}^{2}$, perímetro de 22,2 $\mathrm{Km}$ e comprimento do canal principal de $24,1 \mathrm{~km}$. A microbacia do córrego Buracão possui área total de $29,5 \mathrm{~km}^{2}$, perímetro de $22,2 \mathrm{Km}$ e comprimento do canal principal de 24,1 $\mathrm{km}$. O coeficiente de compacidade $(\mathrm{Kc})$ determinado do córrego Buracão foi de 1,15 e o índice de circularidade (Ic) de 0,50, que associados ao fator forma (Kf) de 0,70 indicam 
o formato alongado da microbacia e conseqüentemente a diminuição do risco de enchentes na área. A densidade de drenagem (Dd) obtida para a bacia em estudo foi baixa $\left(0,81 \mathrm{~km} \cdot \mathrm{km}^{-2}\right)$. A sinuosidade do curso de água principal (Sin) é um fator controlador da velocidade de escoamento. A Sin obtida foi de 1,27 , que associada à baixa declividade do curso de água principal $(2,00)$ e da bacia $(2,00)$ indica que a água escoa lentamente, diminuindo a possibilidade de ocorrência de processos erosivos no leito do córrego. O Coeficiente de Rugosidade (Rn) foi de 11,93, que segundo Rocha e Kurtz (2001), a área tem aptidão agrícola para florestas e reflorestamentos. Com relação a esta declividade obteve-se o valor de 10,65\%, que corresponde a um relevo ondulado, segundo a classificação proposta pela Embrapa (1979).

\section{CONCLUSÕES}

A rede de drenagem tem padrão dendrítico e ramificação de quarta ordem.

A área da microbacia tem formato alongado e mínimo risco de ocorrência de enchentes e o relevo da área é ondulado.

A área tem aptidão agrícola para floresta e/ou reflorestamento.

\section{REFERÊNCIAS}

ANTONELI, V; THOMAZ, E.L. Caracterização do meio físico da bacia do Arroio Boa Vista, Guamiranga-PR. Rev. Caminhos da Geografia, Uberlândia, v.8, n.21, p46-58, jun. 2007.

CARDOSO, C.A.; DIAS, H.C.T.; SOARES, C.P.B; SEBASTIÃO VENÂNCIO MARTINS, S.V. Caracterização morfométrica da bacia hidrográfica do rio Debossan, Nova Friburgo, RJ. Revista Árvore, Viçosa, v.30, n.2, Mar./Apr. 2006;

EMBRAPA. Empresa Brasileira de Pesquisa Agropecuária. Serviço Nacional de Levantamento e Conservação de Solos (Rio de Janeiro, RJ). Súmula da 10, Reunião Técnica de Levantamento de Solos, RJ (EMBRAPA-SNLCS. M.1), 1979, 83p.

EMBRAPA. Empresa Brasileira de Pesquisa Agropecuária. Levantamento de reconhecimento de média intensidade dos solos e avaliação da aptidão agrícola das terras do Triângulo Mineiro. Belo Horizonte: EPAMIG, 1982. 526 p. (Boletim de Pesquisa, 1).

SECRETARIA MUNICIPAL DE MEIO AMBIENTE (SEMEA). Diagnóstico Ambiental da Área de Proteção Ambiental (APA) do Rio Uberaba, 2004, $127 \mathrm{p}$. 
STRAHLER, A. N. Geografia Física. Barcelona: Omega, 352 p., 1974.

TONELLO, K.C.; DIAS, H.C.T.; SOUZA, A.L.; RIBEIRO, C.A.A.S.; LEITE, F.P. Morfometria da bacia hidrográfica da Cachoeira das Pombas, Guanhães-MG. Revista Árvore, Viçosa, v.30, n.5, set./out.2006.

TORRES, J. L.R. et al. Análise das características quantitativas e qualitativas da microbacia do córrego Barreiro, afluente do rio Uberaba. Revista Árvore, Viçosa, v.35, n.4, p931-939, 2012. 